\title{
REFLEXÕES: ANSIEDADE FRENTE À ESCOLHA PROFISSIONAL E À PROVA DO VESTIBULAR
}

Originais recebidos em: 30/03/2011

Aceito para publicação em: 13/09/2011

Aline Battisti Archer

Universidade Federal de Santa Catarina alinearcherr@gmail.com

Sabine Heumann

Universidade Federal de Santa Catarina alinearcherr@gmail.com

Silvio Serafim da Luz Filho

Universidade Federal de Santa Catarina alinearcherr@gmail.com temática é fundamental para que o profissional que trabalha com Orientação Profissional possa lidar, da melhor forma, com essa demanda.

Palavras-chave: Ansiedade. Escolha Profissional. Vestibular. Orientação Profissional.

REFLECTIONS: ANXIETY FACING THE PROFESSIONAL CHOICE AND ADMISSION EXAM

\section{Resumo}

O objetivo deste artigo é analisar os relatos relacionados à ansiedade, tanto frente à escolha profissional quanto em relação à prova do vestibular, de jovens que participaram em 2010 do projeto de extensão de Orientação Profissional, executado no Serviço de Atenção Psicológica (SAPSI) da UFSC. A análise foi feita a partir dos relatos obtidos nas entrevistas individuais iniciais e de devolução da orientação. Por meio desses relatos, pode-se perceber que o momento do vestibular parece potencializar a ansiedade, já que ele pode representar uma passagem para o mundo adulto e uma possibilidade de sucesso perante a sociedade. Além disso, a busca pela certeza da escolha do curso é recorrente. Por estas razões, é importante que o orientador profissional esteja atento e preparado para atender as necessidades desses sujeitos. Portanto, discutir tal

\begin{abstract}
This article aims to analyze the reports about anxiety related by the students when facing the admission exam to the University and the career choice, in year of 2010. These students participated of the Professional Orientation Extension Project, realized at the Psychological Care Service (SAPSI), at the Federal University of Santa Catarina. For this survey, it was used the reports obtained from the personal interviews applied before and after the orientation. The reports show clearly that the moment of the admission exam seems enhance the anxiety when the students don't have enough information about the test, the University courses and career. It's primordial that this subject be discussed, giving to the professional who works with Professional Orientation knowledge to work better with the target.
\end{abstract}

Keywords: Anxiety. Professional Choice. Admission Exam. Professional Orientation. 


\section{ESCOLHA PROFISSIONAL E O VESTIBULAR: UMA DUPLA ANSIOGENICA}

A adolescência se caracteriza por ser uma fase de limbo, na qual o jovem vivencia diversos conflitos, perdas, além do "problema vestibular". Em relação a este último, o adolescente não é só desafiado no seu próprio desempenho, mas também no seu significado como pessoa, já que o vestibular pode ser visto como uma porta de entrada ao mundo dos adultos, no qual o trabalho ocupa um papel central. Este, na sociedade capitalista, tem um papel bastante significativo na formação da identidade do ser humano como ser social (DIAS; SOARES, 2009). Em vista disso, o momento da escolha profissional faz-se de grande importância.

O vestibular, implantado legalmente em 1911, é um exame formal, efetuado pelas instituições de ensino superior, que visa selecionar quantitativa e qualitativamente os candidatos que afluem a seus cursos de nível superior. As universidades classificam seu corpo discente de acordo com o número de vagas disponível e pré-fixado, aplicando prova de capacidade intelectual ou de seleção vocacional (INSTITUTO EUVALDO LODI, 1972).

Apesar de esse exame ser uma problemática nacional, a título de pesquisa destacouse apenas a realidade da UFSC, pois os pré-vestibulandos que compuseram a amostra, descrita posteriormente, eram candidatos ao vestibular dessa instituição.

A UFSC oferece 83 cursos e figura entre as melhores Instituições Federais de Ensino Superior (IFES) do Brasil e da Região Sul. No vestibular dessa universidade, o número de inscritos vem crescendo gradativamente ao longo dos anos. Em 2008 havia 30.612 inscritos; este número passou para 30.854 em 2009. No vestibular de 2010, por sua vez, aumentou para 32.524. O total de vagas oferecidas aumentou do ano de 2008 para o ano de 2010 de 4.095 para 6.021, e, em cursos como Medicina, a concorrência chegou a 59.81 candidatos para cada vaga disponível (UFSC, 2010). Esses dados explicitam a importância de se discutir essa temática, já que caracterizam uma diferença considerável entre candidatos e vagas, o que acaba por resultar num grande número de vestibulandos que ficam fora da universidade.

Diante desse cenário, é válido ressaltar que a obtenção de uma aprovação na prova do vestibular envolve, além do estudo, outros fatores; por exemplo, a condição emocional do sujeito que a realiza (WACHELKE, BOTOMÉ, 2005).

Em relação à condição emocional do vestibulando, o medo, o estresse e a ansiedade se fazem presentes, já que o vestibular pode acarretar um sentimento de perda em relação ao convívio com os amigos e ao lugar onde nasceu, bem como uma necessidade de o estudante assumir, de maneira autônoma, o seu estudo (BIANCHETTI, 1996). Além disso, a cobrança 
da família, de amigos e do próprio meio social para que o estudante obtenha a aprovação contribui, principalmente, para o surgimento da ansiedade (RODRIGUES; PELISOLI, 2008).

Conceitua-se ansiedade como sendo uma antecipação receosa de algo que no futuro se apresentará, sendo uma condição caracterizada por apreensão, tensão ou insegurança (NEMIAH, 1981; NIEMAN, 1999). Portanto, a intensidade na qual a ansiedade se manifesta está relacionada à pressão imposta sobre o indivíduo (SINGER, 1982). É válido ressaltar que há diferentes tipos de ansiedade: ansiedade traço e ansiedade estado. A primeira refere-se a diferenças individuais que são em certo grau estáveis, ou seja, não se alteram significativamente ao longo do tempo. Por outro lado, a segunda diz respeito a um estado emocional transitório, o qual se caracteriza por sensações desagradáveis de apreensão e tensão em decorrência de um fato específico (ANDRADE; GORESTEIN, 1998).

D'Avila e Soares (2003) realizaram um estudo em dois momentos com 549 estudantes. No primeiro utilizaram questionários preenchidos via Internet, e no segundo foram executadas entrevistas no dia da realização do vestibular. Os pesquisadores verificaram que, um mês antes da prova do vestibular, os candidatos vivenciaram sentimentos de ansiedade e angústia, devido ao medo da reprovação e ao medo de decepcionar a família.

Rodrigues e Pelisoli (2008) complementaram tais inferências, ao realizarem uma pesquisa na qual foram avaliados 1.046 estudantes, os quais responderam a um questionário estruturado, com questões sociodemográfica, e à Escala Beck de Ansiedade. ${ }^{1}$ Foi observado que $23,5 \%$ dos vestibulandos apresentaram ansiedade considerada grave ou moderada, sendo os maiores níveis apresentados pelas candidatas do sexo feminino. Neste mesmo estudo, constatou-se, também, que a importância dada pelo adolescente no processo de preparação para o vestibular, ao considerá-lo um momento decisivo na sua vida, foi um fator que se associou à sensação de maior ansiedade por esses candidatos.

Ainda que não bastasse, a decisão para a escolha profissional é outro fator que contribui para a geração de ansiedade. Diante disso, a Orientação Profissional (OP) apresentase como uma possibilidade de o sujeito lidar com tal escolha de maneira menos ansiosa. $\mathrm{O}$ principal objetivo da OP é auxiliar os sujeitos no seu processo de tomada de decisão em relação à sua profissão (LUZ FILHO, 2002).

A Orientação Profissional, de acordo com Muller (1988), caracteriza-se por um processo, uma evolução na qual o orientando reflete sobre a questão e busca caminhos

1 A Escala Beck de Ansiedade é, provavelmente, a medida de autoavaliação de ansiedade mais comumente utilizada tanto em pesquisa quanto em clínica (MARCOLINO et al., 2007). 
possíveis para sua elaboração, não se trata, portanto, de uma prescrição do tipo médica ou mágica. Cabe ainda enfatizar que a escolha profissional pertence exclusivamente ao sujeito, e que é realizada dentro das possibilidades reais do momento dessa escolha, por isso é limitada e não definitiva. Em relação a este último aspecto, é importante ressaltar o caráter momentâneo da escolha, já que ocorre em um determinado contexto da vida do sujeito e envolve tanto as esferas sociais e pessoais quanto as familiares (SOARES, 1993).

Para Luz Filho (2002), a escolha profissional se equivale à escolha de um estilo de vida, de um papel na sociedade, e, para isso, é necessário que o orientando desenvolva autoconhecimento, tenha informações sobre as profissões, discernimento para perceber o que pode estar influenciando essa tomada de decisão, já que a falta desses fatores é bastante ansiogênica. Além disso, qualquer escolha é um fator gerador de ansiedade, visto que escolher é decidir dentre uma série de possibilidades aquela que parece melhor naquele momento e, assim, deixar para trás tantas outras que não foram escolhidas (SOARES, 1993).

A partir das considerações acima, o presente artigo objetiva analisar os relatos relacionados à ansiedade, tanto frente à escolha profissional quanto em relação à prova do vestibular, de jovens que participaram da Orientação Profissional realizada no Serviço de Atenção Psicológica (SAPSI). Esse material pretende servir de subsídio para profisssionais que trabalharão nesse campo de atuação.

\section{PROCEDIMENTOS METODOLÓGICOS}

O presente estudo foi desenvolvido a partir da experiência de estudantes do curso de graduação em Psicologia da UFSC com o trabalho em Orientação Profissional, realizado junto ao Núcleo de Orientação Profissional e de Carreira. Participaram da pesquisa 16 vestibulandos (seis do sexo masculino e dez do sexo feminino), com idades variando entre 16 e 24 anos, da comunidade de Florianópolis e da Grande Florianópolis. Esses vestibulandos buscaram o trabalho de Orientação Profissional realizado no SAPSI, do Departamento de Psicologia da UFSC, durante os meses de outubro e novembro de 2010.

$\mathrm{O}$ estudo foi desenvolvido em quatro momentos, sendo o primeiro e o último constituídos por entrevistas individuais e os demais por aplicação de instrumentos psicológicos. As entrevistas eram semiestruturadas e continham questões que buscavam investigar aspectos gerais da vida do sujeito, como rotina e lazer, as expectativas em relação 
ao trabalho de Orientação Profissional e a percepção do sujeito frente a sua escolha. As entrevistas tiveram duração média de uma hora.

No que diz respeito aos instrumentos, utilizaram-se: o Teste das Dinâmicas Profissionais (TDP); a Bateria de Provas de Raciocínio/Forma B (BPR-5); a Escala de Maturidade para a Escolha Profissional (EMEP); e o Questionário de Avaliação Tipológica (QUATI). Por fim, realizou-se uma entrevista devolutiva com o intuito de repassar as informações obtidas por meio dos instrumentos e finalizar a orientação.

Para o desenvolvimento deste estudo, atentou-se às falas trazidas nas entrevistas individuais iniciais e de devolução. Além disso, realizou-se uma análise qualitativa dos relatos, os quais se relacionavam com o tema. A interpretação desses relatos deu-se à luz da teoria crítica de Vigotski. Optou-se por essa contribuição teórica, por ela desenvolver uma concepção de homem como um modelo histórico-social, ou seja, construído ao longo de uma história de vida, a partir das relações com o mundo e com outros homens.

\section{RESULTADOS E ANÁLISE}

A partir das entrevistas individuais realizadas nesse processo, buscou-se analisar as expectativas dos orientandos frente à Orientação Profissional e ao vestibular. No decorrer dessas entrevistas, a temática ansiedade fez-se bastante presente. Os discursos dos adolescentes eram repletos de dúvidas e de uma busca pela certeza em relação à escolha da sua profissão, como fica claro em alguns trechos em destaque:

1 - "Estou em dúvida sobre que profissão escolher, essa é uma decisão muito importante, preciso ficar segura, não quero ter que trocar depois" (L., 16 anos, $2^{\circ}$ ano do Ensino Médio).

2 - "Vim saber se é isso mesmo". (V., 18 anos, estudante de cursinho).

3 - "Eu queria fazer engenharia, mas eu não sei o que faz um engenheiro. Historiador eu sei, que a minha mãe é historiadora." (C., 16 anos, $2^{\circ}$ ano do Ensino Médio).

4 - “Gosto muito de Medicina, mas não sei se é isso". (G., 16 anos, $2^{\circ}$ ano do Ensino Médio).

5 - "Espero sair daqui com uma decisão tomada, para não perder tempo com isso no ano que vem, e conseguir me fixar só nos estudos" (J., 16 anos, $2^{\circ}$ ano do Ensino Médio). 
6 - "Eu sempre quis fazer arquitetura, mas tenho medo que depois não consiga arranjar trabalho" (M., 18 anos, estudante de cursinho).

7 - "Fiz UDESC, e não gostei e desisti. Agora fico mais indeciso, porque tenho medo de não gostar de novo". (V., 19 anos, estudante de cursinho).

8 - “Como é a grade do jornalismo? [...] Aonde se encontra?" (F., 19 anos, estudante de cursinho).

9 - "Quis porque vi numa novela quando pequena" (Curso de Direito). (T., 18 anos, estudante de cursinho).

Por meio dos primeiros sete relatos acima, observa-se a importância que essa escolha tem para os orientandos, já que se demonstram preocupados em ter certeza de qual profissão escolher, sem perceber que tal escolha é fruto de um processo que envolve informação, conhecimento de si mesmo e outros fatores. Além disso, é possível perceber que as expectativas que trazem consigo em relação à Orientação Profissional dizem respeito à busca por um resultado imediato e definitivo. No entanto, é importante ressaltar que a OP não se propõe a dar um resultado, ela se constitui por um processo, no qual o orientando é o sujeito ativo, que decide sua própria profissão (MULLER, 1988; SOARES, 1993).

Outra observação relevante refere-se à ausência de conhecimento sobre a realidade sócio-profissional, como pode ser verificada no terceiro, quarto, sexto, oitavo e nono relatos. Esses sujeitos alegaram desconhecer informações sobre os variados cursos, a carga horária destes, o dia a dia do profissional e as fontes para pesquisar esses dados, o que, de acordo com Luz Filho (2002), é indispensável para a decisão da escolha, e é uma das funções da Orientação Profissional contribuir nesse sentido, não oferecendo essas respostas, mas criando condições para que o orientando consiga encontrá-las.

As expectativas frente à escolha não são as únicas que aparecem nesse momento, é possível observar questões referentes ao momento de avaliação do vestibular: tempo para a execução da prova; formato com que ela é organizada (questões somatórias e discursivas, no caso do vestibular da Universidade Federal de Santa Catarina); e tema da redação. Isso pode ser percebido nos comentários abaixo: 
1 - "Porque é federal, falam que é uma das melhores, é muito concorrida, a prova é muito difícil, acho que não estou confiando em mim mesma." (J., 16 anos, $2^{\circ}$ ano do Ensino Médio).

2 - "Como as questões são de somatória, vou me ligar em assinalar somente as que eu tiver certeza. Diferente do que eu fiz ano passado." (V., 18 anos, estudante de cursinho).

3 - "Fico nervosa com o último dia de prova, porque tem as discursivas e a redação." (P., 17 anos, estudante de cursinho).

4. "Os três dias são muito cansativos, ainda mais verão" (A., 17 anos, $3^{\circ}$ ano do Ensino Médio).

Com os trechos descritos, fica clara a importância que o vestibular tem para os jovens, visto que se mostram preocupados frente à prova, relatando incômodos, inseguranças, nervosismo. Diante disso, supõe-se que tal preocupação seja indicativo de ansiedade estado. Segundo D'Avila e Soares (2003), os vestibulandos apresentam um alto nível de ansiedade um mês antes da prova do vestibular, pois vivenciam sentimento de medo e angústia em relação à reprovação e à possibilidade de decepcionar a família.

Além de a preocupação com a prova ser um indício de ansiedade estado, o vestibular representa um momento de transição entre a adolescência e o mundo dos adultos e uma possibilidade de se atingir ou não o sucesso, esse fato por si só pode ser uma fonte de ansiedade estado. Isto pode ser identificado nos relatos abaixo:

1 - "Sou muito paranóica, o vestibular me deixa louca" (T., 16 anos, $2^{\circ}$ ano do Ensino Médio).

2 - "Preocupo-me muito com as minhas notas desde já, preciso me acalmar, tenho medo de não conseguir!" (C., 16 anos, $2^{\circ}$ ano do Ensino Médio).

3 - "Se eu não passar, não sei o que vai ser de mim" (A., 17 anos, estudante do $3^{\circ}$ ano do Ensino Médio).

4- "O meu irmão passou no vestibular ano passado, 'tá' fazendo engenharia de computação. Agora a minha mãe 'tá' contando muito que eu passe e eu tenho medo de não passar" (S., 18 anos, estudante de cursinho).

5- "Eu não sei o que eu vou fazer no ano que vem se eu não passar agora. Todos os meus colegas já entraram na faculdade" (G., 24 anos, estudante de cursinho). 
7- "Àss vezes eu penso em escolher um curso menos concorrido, tenho muito medo de não conseguir fazer a prova!" (V., 18 anos, estudante de cursinho).

8- “O meu maior medo é da prova de física. Fico muito preocupada com isso!" (A., 17 anos, $3^{\circ}$ ano do Ensino Médio).

9- "Eu fico pensando, como vou fazer no dia da prova, se nas provas do colégio eu já fico nervosa..." (J., 16 anos, $2^{\circ}$ ano do Ensino Médio).

10- "Eu não consigo dormir, fico às vezes pensando que o dia [da prova] 'tá' chegando." (G., 16 anos, $2^{\circ}$ ano do Ensino Médio).

11- "Eu não consigo fazer outra coisa que não seja estudar, eu sempre fico achando que estudo pouco. Como eu vou ter certeza que é o suficiente? [...] Fico com muito medo." (F., 19 anos, estudante de cursinho).

Os exemplos três, quatro e cinco corroboram a afirmação de Rodrigues e Pelisoli (2008) de que a cobrança dos amigos, da família, e do próprio meio social, para que o vestibulando obtenha o sucesso da aprovação, pode contribuir, principalmente, para o surgimento da ansiedade.

Mesmo destacando pontos específicos das entrevistas, é importante discutir a Orientação Profissional como um todo. Percebeu-se uma significativa diferença no conteúdo da fala em relação à primeira e à última entrevista. Na entrevista final, pôde-se perceber que houve uma maior responsabilidade por parte desses jovens, já que muitos compreenderam que a escolha profissional é complexa e envolve multifatores, os quais foram discutidos ao longo dos encontros, e promoveram, assim, o autoconhecimento. Além disso, os orientandos pesquisaram informações sobre os cursos, realidade profissional das carreiras que lhes interessavam e questões referentes à prova. A partir desse envolvimento, os adolescentes afirmaram estarem menos ansiosos, tanto em relação à prova quanto em relação à escolha da profissão.

Outro fator que contribuiu, observado através dos relatos, para que a ansiedade se tornasse mais amena, foi a conscientização de que essa escolha não é definitiva e ocorre a partir do que a pessoa conhece e vive naquele momento (SOARES, 1993). Antes da orientação, os estudantes percebiam esse momento como determinante e único, o que vai ao encontro da pesquisa realizada por Rodrigues e Pelisoli (2008), a qual afirma que os vestibulandos consideram essa escolha como decisiva para as suas vidas. É válido afirmar, ainda, que tal conscientização se deu, principalmente, devido às conversas que ocorreram durante toda a orientação. 
Diante disso, pode-se perceber que o trabalho de Orientação Profissional, aqui descrito, auxiliou a tomada de decisão em relação à escolha profissional, levou o aluno a conhecer as possibilidades de atuação de determinados profissionais, o mercado de trabalho de uma forma geral e aumentou o autoconhecimento desses participantes. No entanto, esse formato apresenta algumas limitações, como a questão do tempo: um processo de OP realizado em um período mais longo e em um maior número de sessões poderia oferecer um resultado mais concreto; a dificuldade em encontrar profissionais dispostos a palestrar para esses orientandos sobre o mercado de trabalho e as possibilidades de atuação de determinada área também apareceu como um ponto deficitário.

\section{CONSIDERAÇÕES FINAIS}

$\mathrm{O}$ vestibular é sim um processo gerador de ansiedade, quer em relação à prova, quer em relação ao momento que a antecede, ou seja, o processo de escolha e a tomada de decisão. Estes trazem sentimento de angústia, não só porque a prova é tida, por muitos jovens, como um momento determinante de suas vidas, mas também por ser uma opção que, por si só, envolve abrir mão de uma série de outras possibilidades.

Por meio dos relatos dos orientandos, pode-se perceber que, ao procurar a Orientação Profissional, os vestibulandos buscam uma certeza em relação à escolha da profissão; no entanto, não se dão conta que esta é fruto de um processo que envolve múltiplos aspectos, como autoconhecimento e informações sobre os cursos. Este último é fundamental para os orientandos. Diante disso, problematizar e possibilitar o acesso a fontes de informação é vital para o desenvolvimento da Orientação Profissional, o que leva os estudantes a criarem maior autonomia e serem, assim, protagonistas do seu processo de conhecer.

No que se refere à ansiedade, o medo de decepcionar a família e de não passar no vestibular, o que talvez represente um fracasso perante a sociedade, são os principais causadores dessa sensação. Portanto, discutir esses fatores é fundamental para que o profissional que trabalha com OP possa atender de melhor forma essa demanda, a fim de possibilitar que o vestibulando lide com essa sensação de uma forma menos prejudicial.

A Orientação Profissional, aqui realizada, apresenta benefícios e limitações. No que se refere a estas, é possível citar o tempo, o número de sessões da OP e a dificuldade de conseguir profissionais disponíveis para palestrar sobre a realidade do mercado de trabalho. 
Todavia, é interessante ressaltar que o número reduzido de sessões também pode ser percebido, a partir de outro viés, como um benefício em momentos em que não se dispõe de um tempo longo para realizar a OP.

No que diz respeito aos benefícios, pode-se citar o auxílio no processo de tomada de decisão em relação à escolha profissional, a partir do autoconhecimento desenvolvido ao longo dos encontros, do conhecimento do mercado de trabalho e das possibilidades de atuação de diferentes profissões. É importante ressaltar que, se tais dificuldades tivessem sido ultrapassadas, as possibilidades em relação aos benefícios seriam ampliadas, e talvez ocorressem, assim, diferenças no processo de reflexão, por parte do orientando, sobre a sua problemática em relação à escolha profissional.

Este estudo buscou contribuir para o desenvolvimento da reflexão sobre o binômio ansiedade e vestibular, juntamente com outros que já foram escritos. No entanto, é importante que o universo acadêmico se atenha mais a esse tema, visto que há ainda muitas possibilidades de discussão.

Dessa forma, é importante que haja uma continuidade do conhecimento científico em relação a esse assunto. Para futuras pesquisas, sugere-se que a amostra estudada seja maior e que envolva diferentes estratos sociais, já que, assim, pode-se verificar uma realidade diferente da estudada aqui, bem como realizar uma análise mais ampla dessa. Também, seria válido que se realizassem outros momentos de diálogo entre o orientador e o orientando, para que haja um maior número de relatos a serem analisados. Além disso, para as próximas pesquisas, ficam as perguntas: até que nível a ansiedade é prejudicial para aquele que está se preparando para uma prova do vestibular? Quais são as diferentes possibilidades de realização da OP que existem para auxiliar a prática do psicólogo?

\section{REFERÊNCIAS}

ANDRADE, Laura H. S. G.; GORESTEIN, Clarice. Aspectos gerais das escalas de avaliação de ansiedade. Revista de Psiquiatria Clínica, v. 25, p. 285-290, 1998. Disponível em: $<$ http://www.hcnet.usp.br/ipq/revista/vol25/n6/ansi256a.htm>. Último acesso em 14 set. 2011.

BIANCHETTI, Lucídio. Angústia no vestibular: indicações para pais e professores. Passo Fundo: EDIUPF, 1996. 
DIAS, Maria S. de L.; SOARES, Dulce H. P.. Planejamento de Carreira: Uma orientação para estudantes universitários. $1^{\circ}$ São Paulo: Vetor, 2009.

D'AVILA, Gerusa T.; SOARES, Dulce H. P. Vestibular: Fatores Geradores de Ansiedade na "Cena da Prova". Revista Brasileira de Orientação Profissional, v. 4, n. 1/2, p.105-116, 2003. Disponível em: $<$ http://www.fafich.ufmg.br/pop/Downloads/artigos-publicados-narevistada-abop/artigos-paravestibulandos/fatores $\% 20$ geradores $\% 20 \mathrm{de} \% 20$ ansiedade $\% 20$ no $\% 20$ vestibular.pdf $>$. Último acesso em 14 set. 2011.

INSTITUTO EUVALDO LODI. Tudo sobre vestibular; levantamento sobre o ensino na Guanabara. Rio de Janeiro: M. M. Edições, 1972.

LUZ FILHO, Silvio S. da. Escolha profissional: projeto de vida e de carreira. Canoas: MASAI, 2002.

MULLER, Marina. Orientação Vocacional: contribuições clínicas e educacionais. Porto Alegre: Artes Médicas, 1988.

NEMIAH, John C. Fundamentos de psicopatologia. 3. ed. Rio de Janeiro: Zahar, 1981.

NIEMAN, David C. Exercício e saúde. São Paulo: Manole, 1999.

RODRIGUES, Daniel G.; PELISOLI, Cátula. Ansiedade em vestibulandos: um estudo exploratório. Rev. psiquiatr. v. 35, n. 5, p. 171-177, 2008. Disponível em:

$<$ http://www.scielo.br/pdf/rpc/v35n5/a01v35n5.pdf.> Último acesso em 14 set. 2011.

SINGER, Robert N. Psicologia dos esportes: mitos e verdades. 2. ed. - Sao Paulo: Harper \& Row do Brasil, 1982.

SOARES, Dulce H. P.. Pensando e vivendo a orientação profissional. São Paulo: Summus, 1993.

UFSC. Comissão Permanente de Vestibular, 2010. Disponível em:

$<$ http://coperve.ufsc.br/outrosVest.php>. Último acesso em 14 set. 2011.

WACHELKE, João F. R.; BOTOMÉ, Silvio P. Comportamento de vestibulandos em relação a organização, gerenciamento e alocação do estudo em períodos de tempo. Interação em Psicologia, v. 8, n. 2, p. 143-153, 2004. Disponível em:

$<$ http://ojs.c3sl.ufpr.br/ojs2/index.php/psicologia/article/viewFile/3263/2622>. Último acesso em 14 set. 2011. 